\title{
Géneros y sexualidades disidentes en la Argentina: de la agencia por los derechos a la legislación positiva ${ }^{1}$
}

\author{
Dora Barrancos²
}

Recepción: 13 de mayo de 2014 / Aprobación: 2 de julio de 2014

"Le droit n'a pas promouvoir une morale sexuelle spécifique sous peine de devenir lui-meme inmoral"

Borrillo, 2009

\section{Resumen}

El artículo examina la evolución de las sexualidades en la Argentina en el contexto de los cambios sociales y culturales ocurridos durante el siglo pasado y las grandes transformaciones de la última década. Durante gran parte del siglo XX la medicina, la psiquiatría y el imaginario común condenaron como patología la homosexualidad. La homofobia tuvo algunos desplazamientos durante el peronismo, pero los Edictos Policiales, normas inconstitucionales creadas por la propia policía, reprimían el ejercicio de la homosexualidad. El movimiento por los derechos de las personas gay surgió a fines de la década de 1960, pero sufrió los embates de la feroz dictadura militar (1976-1983). Con el regreso a la democracia pudo extenderse la agencia con la acción de diversos grupos de activistas, y la epidemia HIV/SIDA fue decisiva para su visibilidad. Por su parte, las manifestaciones de las mujeres lesbianas, aunque aparecidas también en la década 1960, fueron más tímidas en su expresión y por lo general se incorporaron al propio movimiento feminista y al activismo gay. Las personas trans e intersexuales solo pudieron formar colectivos a mediados de la década de 1990 con muchas mayores dificultades para el reconocimiento. Los cambios fundamentales, y poco previstos, ocurrieron en la última década, cuando la Argentina sancionó las dos principales reformas, la ley que autoriza el casamiento entre las personas del mismo sexo y la ley de identidad de género que da garantías de completa igualdad civil a las personas según la identidad de género y sexualidad que manifiesten.

\section{Palabras clave}

Género; sexualidades disidentes; homosexualidad; lesbianismo, personas trans

$1 \quad$ Una versión previa de este trabajo fue presentado como conferencia en el "Encuentro Mujeres a las Urnas: 60 aniversario de elegir y ser electas en Costa Rica", con el auspicio del CIICLA, Universidad de Costa Rica, 27-29 de agosto del 2013.

2 Argentina. Socióloga y Doctora en Historia por la Universidade Estadual de Campinas, Brasil. Profesora Consulta de la Facultad de Ciencias Sociales de la Universidad de Buenos Aires, Argentina. Es Investigadora Principal del CONICET y Directora del CONICET en representación de las Ciencias Sociales y Humanidades desde mayo de 2010. Correo electrónico: barrancosconicet@gmail.com 


\section{Abstract}

The article examines the evolution of sexualities in Argentina, in the context of social and cultural changes during the past century and the great transformations of the past decade. For much of the twentieth century, medicine, psychiatry and common imaginary condemned homosexuality as pathology. Homophobia had some changes during the Peronist regime, but the "police edicts" were unconstitutional rules created by the police itself, and it was very common gay persecution, especially during dictatorships. The movement for the rights of gay people emerged in the late 1960s but suffered the brunt of the military dictatorship (1976-1983). With the resumption of democracy could extend rights agency by the action of various activist groups, and the HIV/AIDS epidemic was decisive for its visibility. Meanwhile, demonstrations of lesbians also appeared in the early 1960s, but they were more timid in their expressions and usually joined the feminist movement itself and gay activism. The trans and intersex people were able to form groups in the mid 1990s with many more difficulties for recognition. Fundamental and unforeseen changes occurred in the last decade, when Argentina sanctioned two main reforms, the law authorizing the marriage of persons of the same sex, and the gender identity law that guarantees full civil equality to people according to gender identity and sexuality declared.

\section{Keywords}

Gender; dissident sexualities; homosexuality; lesbianism; transgender

\section{Resumo}

O artigo examina a evolução das sexualidades na Argentina no contexto das mudanças sociais e culturais do século passado e as grandes transformações da última década. Durante grande parte do século XX, a medicina, a psiquiatria e o imaginário social, condenaram a homossexualidade como uma patologia. A homofobia teve algumas modifcações durante o regime peronista, mas os "decretos da polícia", que eram inconstitucionais pois tratavam-se de normas criadas pela própria polícia, reprimiram a homossexualidade. O movimento pelos direitos dos homossexuais surgiu na década de 1960, mas sofreu o impacto da ditadura militar (1976-1983). Com a retomada da democracia pôde se estender a agência de vários grupos ativistas e foi muito importante para a sua visibilidade a epidemia de HIV/AIDS. As manifestações das mulheres lésbicas- aparecidas também na década de 1960- foram mais tímidas, geralmente ligadas ao ativismo gay e ao movimento feminista. As pessoas trans e intersexuais não foram capazes de formar grupos senão até meados da década de 1990, tendo muitas mais dificuldades para o reconhecimento. Mudanças notáveis ocorreram na última década, com duas reformas civis: a lei que autoriza o casamento entre pessoas do mesmo sexo, e a lei de identidade sexual e de gênero que dá garantias de igualdade civil plena às pessoas, de acordo com o gênero e a sexualidade que elas manifestam.

\section{Palavras chave}

18 Gênero; sexualidades dissidentes; homossexualidade; lesbianismo; pessoas trans 


\section{Introducción}

L

as concepciones dominantes en la Argentina durante el siglo XX estuvieron lejos de atender la cuestión de la soberanía de los sujetos, y hubo un señalado letargo para adherirse a las prerrogativas que otorgaran mayor autonomía individual. La sociedad argentina se vio interrumpida por golpes militares durante buena parte de ese siglo, de tal modo que el Estado de Derecho fue verdaderamente excepcional. Desde 1930, en que un conjunto de fuerzas de derecha puso fin al gobierno constitucional, la interrupción de los gobiernos no tuvo solución de continuidad. La manifestación más acuciante y más dramática de esta saga ocurrió en marzo de 1976 con la instalación del Terrorismo de Estado que hizo desaparecer a miles de personas y que se apropió de cientos de niños nacidos en cautiverio, o arrebatados a su familia a raíz de procedimientos represivos.

Las conformaciones ideológicas plasmaron órdenes combinadas de moral sexual y axiologías ideológicas y políticas sobre el dato angular de atribuir a la Naturaleza una maquinación divina. Un coadyuvante decisivo de esta forja de sentidos fue la Iglesia católica, cuya influencia fue enorme a lo largo de todo el siglo XX, sobre todo a partir de la década de 1920, aunque su membresía parece no haberse caracterizado por el apego a los rituales confesionales. No era solo en los círculos conservadores, orientados angularmente por el catolicismo, que los preceptos morales de la sexualidad tenían férreas líneas prescriptivas consagrando determinadas formas vinculares mientras condenaban otras (Barrancos, 1999).

El patriarcado gozaba de sólida salud a partir de su nuevo empinamiento en el siglo XIX, uno de sus triunfos mayores reposaba en la categoría moral otorgada a las relaciones jerarquizadas de género, y esta presunción fue remodelada por las fuerzas liberales que poco contradijeron las matrices del Antiguo Régimen. Resultaba moralmente inaceptable que las mujeres se desempeñaran en la vida pública, pues el fundamento de esta creencia aludía a la "norma natural" que mandaba ocuparse de la lumbre hogareña, reproducir y asistir a los suyos. Casarse y engendrar era una obligación que se creía dignificaba plenamente a las mujeres. Como es bien sabido, estaba sancionada la vinculación carnal antes o fuera del matrimonio, y de modo particular el adulterio concitaba toda suerte de condenas entre ciertos grupos sociales. En contrapartida, los varones estaban autorizados al ejercicio de la sexualidad "normal", y hasta se sugería que se hallaban más realizados en su masculinidad si acosaban a diferentes clases de mujeres.

Los imaginarios relativos a todos los grupos sociales se adherían a estas fórmulas, aunque hubo excepciones, y esas voces disonantes, que no por menguadas estuvieron desprovistas de estridencia -pensemos tan solo en 
las feministas y en quienes las acompañaban-, las representaciones hegemónicas sobre la moral que correspondía a cada sexo tuvieron un largo efecto social. Por lo que no puede sorprender, que en el cóncavo de las concepciones morales patriarcales, el propio feminismo, tuviera muchas dificultades para lidiar con la sexualidad, y desde luego la Argentina no fue una excepción. Tal como he señalado en otro lugar:

Es en este cuadro de doble rasero moral y de sometimiento al deseo masculino, que debe entenderse que las feministas se apegaran a la idea de que la sexualidad era una manifestación penosa, tal vez una anomalía, un atributo del patriarcado que debía por lo menos inhibirse (Barrancos, 2011, 7).

Las cuestiones sexuales eran temidas, propias de las "malas mujeres", y aunque no faltaron en el Río de la Plata activistas feministas preocupadas por la "educación sexual" -tal es el caso de la célebre Paulina Luisi que actuó en la Argentina y en el Uruguay (Sapriza, 1999)-, las expresiones en materia de sexualidad provinieron del anarquismo (Barrancos, 1990, 240-264). Pero no hay cómo contradecir la idea de una extensa censura a la cuestión del placer sexual de las mujeres. Solo un antiguo miembro de la agencia libertaria, el conocido educador Julio Ricardo Barcos en su libro Libertad sexual de las mujeres $^{3}$, transgredió la canónica oclusión destinada a las mujeres decentes. Pero bien analizado este texto precursor -cuyas actividades acarrearon no pocos problemas con las autoridades educativas-, se situaba en la consumación sexual, celebrando sobre todo su consecuencia procreativa.

La homosexualidad resultó un problema cuasi escatológico aún más allá de los ámbitos académicos, que de modo inveterado lo concebían como una patología. En el tránsito a la Argentina moderna, el tópico era indigno de ser tratado en lugares públicos, y la condena de los "amorales" -como se caracterizaba a quienes inclinaban sus sentimientos hacia personas del mismo sexo-, no conoció atenuantes salvo escasísimas excepciones. El escritor José González Castillo, de ideas libertarias ${ }^{4}$, sorprendió en 1915 con la pieza teatral Los invertidos (González, 1915). No se trataba precisamente de una exculpación en nombre de una actitud signada por las notas atenuantes, sino de poner en evidencia la moral hipócrita de la clase social dominante, la práctica de la homosexualidad. A medida que se extendieron las filiaciones a la derecha por parte de determinados grupos sociales -en especial pertenecientes a las clases altas y medias- y que se expandieron las posiciones autoritarias entre las décadas 1930 y 1940, la persecución a los "invertidos" adquirió formas más visibles y más agresivas. Resultó muy sonado un episodio en el Colegio Militar de la Nación, en septiembre de 1942, cuando un grupo de cadetes, a propósito de un encuentro festivo, fueron denunciados

3 La primera edición es de 1921. Me baso en la reedición de 1935 (5ª edición). Buenos Aires: Editorial Araujo.

4 Existen estudios que muestran mayor apertura prodigada por miembros de la anarquía a la cuestión homosexual, ver especialmente Cleminson (2008). 
por prácticas amorales (Bazán, 2004). Hubo un severísimo escarmiento con el objeto de disuadir por completo cualquier tentativa de emulación.

Ya instalado el peronismo, a mediados de la década de 1940, se produjeron transformaciones y para Pablo Ben y Omar Acha (2005), fue el momento no solo de una mayor tecnificación psicológica del concepto de "homosexualidad", sino que se produjo la definición social y la identificación colectiva de los homosexuales en la Argentina. Lo que los autores subrayan es que pudieron ser visibilizados como una determinada comunidad en el cuadro de las diferencias. No faltaron episodios de censura y de franca hostilidad, sobre todo por obra de los Edictos Policiales -normas creadas por el sistema policial a espaldas de las garantías constitucionales-, pero se evidenciaron tratamientos ambivalentes, como lo muestra el caso del conocido cantor homosexual español Miguel de Molina, quien había llegado al país huyendo del franquismo, y que fuera hostigado a instancias de la Embajada de España, debiendo refugiarse en México. Pero, en 1946 fue la propia Eva Perón quien lo hizo regresar, y de Molina desarrolló una halagüeña carrera artística durante el período peronista (Ben y Acha 2005, 218). En contraste, y tal vez justamente por la mayor identidad del "grupo homosexual", el "clima de época" resultaba irrespirable para quienes eran opositores al peronismo, tal como ocurrió con el escritor argentino radicado en Francia -y que llegó a ser miembro de la Academie Francaise-, Héctor Bianciotti (Bianciotti, 1992, 80-87).

Solo en los continuos movimientos de la década de 1960, en el clima de los cambios que condujeron a la radicalidad masiva de los segmentos juveniles y de las capas medias urbanas, en buena medida aliadas con las clases populares, se alteraron bastante los patrones de la moral sexual en la Argentina. Hubo circunstancias locales para la radicalidad política de la que participaron de modo activo las mujeres, pero no deben dejarse de lado los estremecimientos internacionales, la Guerra Fría, la guerra caliente de Vietnam, la Revolución Cubana, el proceso de descolonización africano, para señalar los más importantes, con consecuencias sobre los grupos estudiantiles que protagonizaron las conocidas revueltas de esa década. La segunda ola feminista apenas golpeó la orilla argentina, toda vez que una buena parte de la población femenina que se adhirió a diferentes agencias urgidas por la transformación social, prefirió este cometido mayor al de sostener sus propios derechos. Pero lo cierto es que, se modificaron en buena medida las estrictas normas morales acerca de la virginidad, de las relaciones sexuales entre varones y mujeres, y se amplió para las jóvenes de clase media la autorización del conocimiento carnal, aunque los vínculos no se consagraran ante el Registro Civil (Cosse, 2010).

En esos años, también asomaron los primeros atisbos de demanda de reconocimiento por parte de las primeras organizaciones de varones homosexuales. Se trató de una cortísima primavera porque la cuestión homosexual carecía de respaldo no solo por parte de los sectores más conservadores, sino de las diferentes agencias ideológicas y políticas que procuraban trans- 
formaciones radicales. No puede dejar de considerarse la irrupción de la última feroz dictadura en marzo de 1976. El ciclo abierto entonces extinguió las formas díscolas de la sexualidad, y los represores fueron especialmente brutales con quienes resultaban marcados por sus preferencias homosexuales. También las mujeres sufrieron en mayor medida el doble lazo de la tortura y la violación. Las perversiones de los torturadores estaban, de manera particular, dirigidas a abusar, a penetrar zonas erógenas en forma colectiva, a perforar esfínteres, y no pocas veces a hacer estallar órganos vinculados a la sexualidad o a la reproducción (Lewin y Wornat, 2014, 215-262).

Solo con la reconquista del Estado democrático, se empinaron los movimientos emancipatorios de las mujeres y de los sujetos sexualmente diversos. Este texto se ocupará de estos últimos, revisitando sus luchas por el reconocimiento, los desafíos que atravesaron hasta la conquista de leyes fundamentales y lo que todavía deben alcanzar para la ciudadanía igualitaria. No se trata de una saga exenta de contradicciones y menos aún de quebrantos y de cismas. Y nada más lejos de mi perspectiva que el enunciado de una "identidad" unívoca: si algo muestra la articulación política de los diferentes movimientos reivindicativos de gays, lesbianas y personas trans, es su inconmensurable capacidad de rechazar las etiquetas y las caracterizaciones estereotipadas. De la misma manera, las manifestaciones heterosexuales resisten cualquier soldadura identificatoria definitiva. Decirse heterosexual, de igual manera que enunciarse gay, lesbiana o travesti, no origina ninguna formulación inexorable, y mucho menos encriptada, de la personalidad. Mi punto de vista es que la sexualidad es una dimensión que no autoriza, absolutamente, a ninguna forma de encasillamiento óntico, circunstancia que proviene de una operación social del "lado de afuera", o en término de Judith Butler, "la condición discursiva del reconocimiento social precede y condiciona la formación del sujeto; no es que se le confiera el reconocimiento a un sujeto; el reconocimiento forma a ese sujeto" (Butler, 2005, 317). El deseo sexual y la sexualidad discurren en una perspectiva, que no puede estar condenada a trazos inmarcesibles y a estabilidades indeclinables, en todo caso se trata de negociaciones permanentes de cada individuo en contextos históricos y sociales determinados.

Este trabajo hace foco en tres fenómenos del recorrido de la sexualidad en la Argentina, a saber: la cuestión de la homosexualidad masculina, las vicisitudes para la construcción de una identificación lésbica colectiva, y los más recientes desafíos originados por el movimiento de las personas trans para quienes, sin lugar a dudas, ha sido mucho más difícil acceder al reconocimiento.

\section{De la homosexualidad masculina a la formulación gay}

Las relaciones amatorias entre personas del mismo sexo han existido en todas las sociedades y en todos los momentos de la historia, pero el acierto semántico gnoseológico y político del término "homosexualidad" remite a la 
segunda mitad del siglo XIX (Foucault, 1991; Boswell, 1992). El término fue acuñado por el médico austro-húngaro Karoly María Benkert -popularizado en 1869 como Karoly Maria Kertbeny- casi al mismo tiempo que lo hiciera el psiquiatra prusiano Carl Friedrich Westphal (Gay, 1992, 211), en un contexto de rápidas transformaciones económicas y de consolidación del dominio normativo científico moderno, aunque también de rupturas contestatarias, de insurgencias personales y colectivas.

No puede sorprender que apareciera dentro de la disciplina médica psiquiátrica la figura amigable de Magnus Hershfeld, quien evidenció una especial comprensión del fenómeno de la homosexualidad -aunque inexorablemente ligado a cuestiones neurofisiológicas-, y lo llevó a ensayar el Comité Científico Humanitario que integraron destacadas figuras socialdemócratas como Augusto Bebel y Eduardo Bernstein. El Comité estaba destinado a proteger de modo "humanístico" a los homosexuales, a brindar información médica adecuada, y a atenuar seguramente el pánico frente al comportamiento homoerótico (Gay, 1992, 215; Llorca Díaz, 1996, 11; Gordon, 2000).

La imaginación científica normativa exhibió de modo amplio el designio de penalizar las prácticas homosexuales como anormalidades y perversiones, y una vasta producción de consideraciones morales invadió los tratados médicos, psicológicos y educativos de ese fin de siglo. Un párrafo especial merece el famoso médico psiquiatra austríaco Richard von Krafft-Ebing y su conocido tratado Psychopathia Sexualis (1886), en el que describió muy diversas manifestaciones de las patologías con largos enunciados acerca de la homosexualidad, cuyas repercusiones sacudieron diversos ambientes sociales. Lo notable era el contraste con la experiencia homoerótica extendida en ese siglo, sobre todo a propósito del incremento de los encierros de adolescentes en ámbitos educativos, tal como ocurrió bajo el régimen de las Publics Schools de Inglaterra (Honey, 1992, 223). No puede dejar de mencionarse a Havelock Ellis, notable ensayista también de nacionalidad austriaca, entre las menguadas voces que interpretaban la condición del homosexual con intentos mucho más conciliadores. Ellis escribió con John Addington Symonds, Sexual Inversion, un ensayo de características singulares que debió ver la luz primero en alemán en 1896. Piénsese en que el momento coincidió con la condena de Oscar Wilde, a quien se le aplicó la nueva normativa inglesa, por cierto más dura que la anterior. Más allá de este tenebroso episodio, no parece correcto concluir que la mayor eficacia del lenguaje "científico", relativo a la homosexualidad, haya producido una cadena de modificaciones de la ley penal occidental en orden a agravar las sanciones (Gay, 1992, 207-208).

En la Argentina, en ese fin de siglo, se abrió paso una sólida perspectiva disciplinar vinculada a la neurología y la psiquiatría, y el problema de la homosexualidad resultó trajinado por diversos especialistas que en ningún caso se apartaron del encuadre patológico, ingresando de lleno en el campo de la criminología. Como un signo de la modernidad, este nuevo campo alardeaba de 
autorizaciones para condenar el crimen de los vínculos carnales entre personas del mismo sexo, atribuyendo sobre todo a los homosexuales varones las peores características. Pero es muy discutible si este fermento de "cultura científica", como ha sostenido Jorge Salessi, se transformó en una obsesiva persecución de los homosexuales (Salessi, 1995). Se trataba de preocupaciones intelectuales que encontraban su contraparte en el extendido imaginario social homofóbico, en la apuesta canónica a la virilidad como fuente de legitimaciones, y ambos términos encontraban auspicio en los designios del propio Estado que abjuraba de cualquier circunstancia adventicia sexual capaz de poner en riesgo a la integridad de la Nación. Pero, no se constata una cacería indiscriminada en las primeras décadas del siglo XX, no se registró nada parecido al "pánico sexual", tal como sostienen Ben y Acha (Ben y Acha, 2005, 219).

A inicios de la década de 1940 fueron engendrándose, en los grandes centros urbanos, los ya citados Edictos Policiales. Se trató de normas inconstitucionales, elaboradas por los propios cuerpos de policía y sancionadas fuera de cualquier orden legislativo. Los Edictos daban capacidad a las fuerzas policiales para actuar en materias tales como la prostitución y lo que se consideraba franca perturbación de las buenas costumbres, como el uso de ropas femeninas por parte de varones, originando muchas veces la detención de personas -a menudo bajo la forma de redadas por ocasión de reuniones-, además de otras arbitrariedades que se acentuaron bajo los gobiernos de facto (Bazán, 2004).

Bajo la dictadura del general Juan Carlos Onganía (1966-1970) -adherente católico fervoroso- la censura llegó a marcas insospechadas (se prohibieron óperas, ballets, exhibiciones artísticas y numerosos filmes) y las policías -tanto la federal como las que respondían a los estados provinciales- redoblaron las intervenciones de control de la moral. Resultó célebre la gestión del Comisario Luis Margaride que no dudaba en requisar los lugares privados -aún los hoteles debidamente registrados para el encuentro amatorio- con tal de sostener los principios de la moral sexual con signos fundamentalistas. Pero ese interregno coincidió con el fermento de la radicalidad política, como ya he señalado, y el surgimiento de numerosos movimientos políticos y sociales. Uno de esos movimientos fue el Frente de Liberación Homosexual (FLH) que reunió sobre todo a jóvenes intelectuales homosexuales de izquierda (Bazán, 2004, Meccia, 2006, Simonetto 2014).

La historia de FLH tuvo algunos antecedentes, pero el más próximo fue la agrupación denominada Nuestro Mundo, surgida en 1967 a la que dio especial impulso Héctor Anabitarte un joven empleado, militante del Partido Comunista que fuera expulsado de esas filas justamente a raíz de su homosexualidad. Debe recordarse que dos años más tarde se asistiría a la revuelta neoyorkina de Stonewall y un empinamiento de la agencia por los derechos de las personas gays que ya no retrocedería. En 1970 surgió en Buenos Aires el FLH, y además de Nuestro Mundo, otro ariete fundamental fue el grupo Profesionales entre los 
que sobresalían Néstor Perlongher y Sergio Pérez Álvarez (Simonetto, 2014, 26 27). Este último núcleo había surgido en el marco de la pertenencia estudiantil a la Facultad de Filosofía y Letras de la Universidad de Buenos Aires, a la sazón un ámbito de manifestaciones radicalizadas. No fueron pocas las dificultades para conquistar el beneplácito de las agrupaciones de izquierda que pululaban en la época, pues eran comunes los desaires y los rechazos. Las movilizaciones estudiantiles que se originaban en la citada Facultad solían contar con un pequeño núcleo portador de pancartas que indicaban la identificación del FLH, y no hay duda de que se trataba de una auténtica bizarría. Resultaban limitadas las muestras de simpatía entre las columnas de manifestantes durante el interregno 1970-1976 (Bazán, 2004).

Según Patricio Simonetto, el FLH reunía a once agrupaciones -hasta había una autodenominada Católicos Homosexuales de la Argentina- y consiguió extenderse, aunque de manera tímida, en las ciudades del interior del país (Simonetto, 2014, 27). Figuras como la del destacado sociólogo Juan José Sebrelli, y la del notable escritor, Manuel Puig -a la sazón estudiantes-, integraron la primera membresía del FLH. Entre las acciones desplegadas, ligadas de manera estrecha a las expresiones de izquierda del periodo y más particularmente a la radicalidad de la izquierda peronista, se cuenta el haber editado la revista Somos (1973-1976) siendo uno de sus principales objetivos erradicar cualquier significado de "patología" de la identidad homosexual (Simonetto, 2014, 34). De acuerdo con este autor "el cambio de esta categorización sería festejado por el FLH como una posibilidad de pugnar en el campo del conocimiento [...]. Los psicólogos, los sociólogos y los médicos eran considerados por ellos como los 'policías blancos del sistema'” (Simonetto, 2014, 34).

El FLH mantuvo vínculos con una parte del feminismo que se abría paso en la coyuntura, en particular con dos agrupaciones, la Unión Feminista Argentina (UFA) y el Movimiento de Liberación Femenina (MLF). Fueron las activistas de este último quienes contribuyeron a la iniciativa del Grupo de Estudio y Práctica Política Sexual -que mantuvo su autonomía-, cuyo empeño mayor era reflexionar sobre los caminos para derribar los preconceptos morales, denunciar los orígenes patriarcales y capitalistas de la censura del sexo y propiciar el reconocimiento de la sexualidad libre.

El arribo de la dictadura militar en 1976 extinguió la posibilidad del activismo debido a la ferocidad de la persecución desatada. Una parte de los militantes debió abandonar el país, tal fue el caso, entre otros, de Manuel Puig, Héctor Anabitarte y Nestor Perlongher -quien estuvo detenido durante algunos añosuna de las figuras centrales del proyecto. A la salida de la cárcel, Perlongher 
se radicó en Brasil e hizo carrera académica en este país ${ }^{5}$. Hubo que esperar el fin del Terrorismo de Estado para restablecer la agencia por derechos. El antecedente de la década de 1970 pervivió bajo la forma de nuevas reivindicaciones, por parte de quienes asumían la identidad gay en el estreno de la recuperación democrática. Como ha señalado Ernesto Meccia, las nuevas organizaciones gay lograron "politizar la homosexualidad" (Meccia, 2006, 54). No exentas de tensiones, entre la necesidad de mantener el privatismo de la condición -y con esto, un estado permanente de "clandestinidad"-, y la acción política que daba bríos a la manifestación sin tapujos, a la politización de la vida privada, se abrieron paso las organizaciones demandantes de derechos (Figari y Ponce, 2008).

En 1984 surgió la Comunidad Homosexual Argentina (CHA), en la que prevalecieron los principios de visibilidad y reconocimiento dentro de la inscripción mayor de la plena vigencia de los derechos humanos, lo que no puede sorprender en un país que había experimentado dramáticamente su extinción. Sin duda, el contexto de denuncia de los atropellos dictatoriales, la secuela de torturados, muertos y desparecidos -la evidencia monstruosa del secuestro de cientos de niños nacidos en cautiverio o arrebatados a raíz de acciones represivas a quienes se cambió la identidad-constituía también un cauce para la agencia de sujetos históricamente marginados.

Otro tanto, aunque desde luego con mayores márgenes de "legitimidad", ocurría con las reivindicaciones de las feministas. Pero como ha sido subrayado, el espectro del HIV/SIDA obró de modo paradójico para que fuera el propio Estado el que debiera reconocer la existencia de sujetos de sexualidad no heterosexual, e imponerse intervenciones para impedir la extensión de la epidemia (Pecheny, 2001, 1-2; Meccia, 2006). Es bien sabido que la llamada entonces "peste rosa" forjó su sentido agonal en las relaciones homosexuales, y más allá de la censura, de la homofobia que imperaba en buena parte de la sociedad argentina -aunque desde 1973 la Organización Mundial de la Salud erradicara las connotaciones que las asimilaban al desorden patológico-, la acción estatal debió dirigir la atención a las personas de condición gay. De modo muy contradictorio, el miedo a la invasión del retrovirus letal condicionó nuevas formas de exclusión, pero auxilió a la visibilidad de quienes se suponían víctimas exclusivas, aunque a medida que corría la década de 1980, el alerta cundió también para los heterosexuales.

La coyuntura de doble hélice -reclamo por los derechos humanos y necesidad de sofocar el HIV/SIDA- fue estratégicamente empleada por la CHA, que

5 Se debe a Néstor Perlongher (1949-1992) una importante obra como cientista social y en el campo de la literatura, escribió: Alambres (1987); El fantasma del sida (1988); Hule (1989); Aguas aéreas (1990; Parque Lezama (1990); La prostitución masculina (1993); Poemas completos (1997); Prosa plebeya (1997); El negocio del deseo (1999); Evita vive e outras prosas (2001). 
tenía entre sus promotores al joven historiador platense Carlos Luis Jáuregui ${ }^{6}$, quien no vacilaba en solicitar a todos los homosexuales -varones y mujeresque se mostraran, que enunciaran públicamente su preferencia sexual. No en vano fue el organizador de la primera Marcha del Orgullo en 1992, pues entendía que los peores enemigos de los derechos de las personas homosexuales eran el ocultamiento y el sentimiento de vergüenza que solía prevalecer. La gestión de Jáuregui llegó hasta 1987, momento en que las disidencias arreciaron sobre todo porque la CHA focalizaba centralmente sus acciones en la lucha contra el SIDA, y Jáuregui sostenía que además del combate al flagelo había que avanzar en la conquista de derechos (Bellucci, 2010).

En 1989, la Justicia argentina rechazó la solicitud de Personería Jurídica que había realizado la $\mathrm{CHA}$ y aunque la entidad se había difuminado en un arco diverso de nuevas organizaciones -no pocas en el interior del país-, no hay dudas de que siguió siendo una referencia importante para el activismo gay. Como una muestra de los nuevos aires que traía la movilización de los conjuntos discriminados, en 1992, la Justicia debió reconocer como organización civil a la CHA. Pero no fueron pocas las adversidades de este organismo; solo en años recientes, realizó transformaciones que permitieron una ampliación de los puntos de vista, la adopción de una política firme de demandas al Estado y la solidaridad con grupos disidentes (Meccia, 2006).

En efecto, las comunidades trans habían tenido dificultades para convivir con buena parte de quienes integraban la CHA. Pero más allá de las diferencias, durante la primera década del nuevo siglo, ha habido ciertas políticas de unidad que llevaron a transitar reclamos comunes y a obtener logros de enorme significado. Las Marchas del Orgullo se fueron poblando con un número cada vez mayor de participantes y no solo de quienes contrariaban la sexualidad canónica (Meccia, 2006). Cada marcha comporta hoy una multitud de manifestantes con espacio para todo el arco de las diversidades, y no puede soslayarse la renovación que suscita la participación de las personas más jóvenes. No hay duda de que han disminuido las adversidades para el coming out, y que pese a la vertebración homofóbica de la sociedad argentina -una

6 Resulta conmovedora la historia de Carlos Luis Jáuregui, quien falleció de SIDA a los 38 años, en 1996. Lo mismo, unos años antes, había ocurrido con su hermano mayor Roberto, también destacado militante. Carlos había nacido en La Plata en el seno de una familia de clase acomodada. Cursó sus estudios en un importante colegio confesional católico y luego egresó de la carrera de Historia en la Universidad Nacional de La Plata. Sus posiciones ideológicas fueron orientándose hacia la izquierda. Pudo entrar en contacto, debido a sus viajes, con el activismo francés y norteamericano. Además de llevar adelante proyectos organizacionales para la defensa de los derechos de los homosexuales, fue uno de los primeros líderes en adoptar el principio de la más amplia admisión de disidentes sexuales, pues era contrario a la segmentación de las agencias a favor de los derechos de homosexuales y lesbianas de las otras comunidades queer. Escribió La homosexualidad en la Argentina (1987), Buenos Aires: Tarso. En su homenaje, cada 20 de agosto -día en que falleció- se destina a conmemorar el Activismo por la diversidad sexual. Entre otros reconocimientos, una plazoleta de Buenos Aires lleva su nombre (ver especialmente, Bellucci, 2010). 
cantera difícil de extinguir-, se han ganado pasos sustanciales para la identidad gay que, como se verá, ha conquistado derechos civiles fundamentales.

\section{Del tribadismo a las reivindicaciones lésbicas}

A diferencia de la homosexualidad masculina, que podía ser escudriñada con mínimas evidencias -que sonaban siempre escandalosas-, los tratos sexuales entre mujeres pudieron carecer de estridente visibilidad y tal vez por eso mismo, resultaron atenuadas las oportunidades de condenas públicas. Por lo general, de "eso" no se hablaba; al final, dos mujeres podían convivir juntas sin que la vecindad pusiera en sospecha la índole de sus vínculos, y no faltan ejemplos sobre esta circunstancia como ocurrió con la larga relación que mantuvieron Ada Elflein -periodista y ensayista de inicios del siglo XX- y Julieta Gómez Paz (Szurmuk, 1996, 339). En algunos círculos de élite, las mujeres que orientaban su sexualidad hacia otras mujeres, solían autodefinirse como betters, esto es como las mejores, y se permitían otras conductas transgresoras como el uso de ropas masculinas, pero el término con certeza resultaba extraño a las mujeres de los grupos sociales subalternos (Fuscova, Schmid y Marek, 1994). El concepto de lesbianismo no se empleó sino hasta la segunda mitad del siglo pasado en la Argentina, y toda la literatura psiquiátrica -y criminológica- utilizaba los términos equivalentes de "tríbadas" o "safistas", como han consignado Ramaciotti y Valobra (en prensa), para referirse a las "anómalas" atracciones entre mujeres.

También, a diferencia de la homosexualidad masculina -aunque hubiera círculos de sociabilidad entre mujeres que cobijaban relaciones eróticas, y designaciones que caracterizaban la singularidad de los intercambios amatorios y sexuales-, no se registra una acción militante explícita sino hasta la reconquista democrática en 1983. Las lesbianas que asomaban al reclamo de derechos de las mujeres se identificaron, sin especial demarcación, con el feminismo de la década de 1970 y se incorporaron al activismo gay de esos años, pero carecieron de signos distintivos específicos (Simonetto, 2014). Ya he introducido el Grupo de Estudio y Práctica Política Sexual, surgido de la convergencia de militantes del FLH y de un núcleo de feministas en 1972, y se tiene la impresión de que menudearon las lesbianas en este emprendimiento. Algunos de sus miembros, en particular Nestor Perlongher y Osvaldo Baigorria, fueron los redactores del documento La moral sexual en la Argentina (1973) en el que se vinculaba la represión y el sometimiento sexual -de las mujeres y de los homosexuales- al orden capitalista?

En la literatura argentina asomaron muy pocas las relaciones amorosas entre mujeres y por lo general de manera elíptica, aunque hubo algunas excepciones.

7 La moral sexual en Argentina-Investigación, Buenos Aires-septiembre de 1973. Debo copia del manuscrito original a Mabel Bellucci. 
Seguramente, la primera novela que escenificó vínculos homosexuales femeninos fue El derecho de matar (1933) de Raúl Barón Biza ${ }^{8}$, una novela iconoclasta - dedicada al papa Pio XI- que respondía a las características de la personalidad del autor quien oscilaba entre las concepciones más libertarias y las más conservadoras. El protagonista realiza una evolución sentimental -y una educación de los sentidos- que se inicia en una localidad semi rural, y tiene como clave a la enigmática y sensual Cleo. Con el propósito de mostrar el desborde del deseo sexual, esta establece un vínculo con la propia hermana del protagonista ya en un ambiente pintado con los trazos paroxísticos que se atribuyen a la gran metrópoli, donde inflexionan los escrúpulos morales. El escándalo suscitado por el libro, llevó a que el gobierno -surgido después de la primera dictadura de 1930- ordenara el secuestro de los cinco mil ejemplares de una lujosa edición, con ilustraciones de marcado empeño provocador (Ferrer, 2007).

Ya a inicios de la década 1960 apareció la novela Un ángel de bolsillo, y aunque la autora, Ofelia Machado Bonet era uruguaya, la trama se refiere a las ciudades de Montevideo y Buenos Aires. La protagonista vive su juventud a fines de la década 1940 y veinteañera, tendrá vínculos amatorios con una lesbiana, casada con un individuo de deplorables características. Se trata de un amor atrapante y turbulento porque la pareja ejerce fuerte dominio emocional sobre la protagonista, quien finalmente resulta abandonada, circunstancia que le ocasionará hondo padecimiento. Más adelante conoce a un joven argentino, perteneciente a una familia de la élite, quien expresa todas las notas del antiperonismo. Su vida matrimonial transcurre en Buenos Aires, en los primeros años del posperonismo, y aunque parece resuelta la cuestión sexual pues sobran las indicaciones sobre sus sentimientos y sensaciones, no dejan de aparecer las sombras del homoerotismo. La novela mereció el segundo premio de la editorial Losada de Argentina en 1959, un dato que no deja de sorprender debido a la temática, aunque no tanto porque en el grupo editorial-originado por el español de ideas republicanas Gonzalo Juan Losada- dominaban las posiciones mentales más progresistas. De la composición de la editorial se ha ocupado especialmente Schwarsztein (2001).

8 Raúl Barón Biza fue un individuo, sin duda, acometido de graves alteraciones de personalidad. Hombre mundano de ideas controvertidas se casó en segundas nupcias con Clotilde Sabattini, hija de Amadeo Sabattini, notable líder del partido Unión Cívica Radical -que había sido gobernador de la provincia de Córdoba-, y a quien había raptado. Después de años de relación turbulenta se separaron. Clotilde, de adscripción feminista, resultó la primera mujer en ocupar una alta función pública, durante el gobierno de Arturo Frondizi (1958-1962) pues se desempeñó como Presidenta del Consejo Nacional de Educación -máximo organismo destinado a la educación primaria-, en la Argentina por esos años. En agosto de 1964, mientras ambos cónyuges participaban de una reunión con abogados para definir los términos de la separación definitiva, Barón Biza le arrojó un vaso con ácido que destruyó parte del rostro de Clotilde, y luego se suicidó. Clotilde fue objeto de varias y muy penosas cirugías. En 1978 también se suicidó arrojándose del balcón del departamento céntrico en la Ciudad de Buenos Aires en el que había sufrido el ataque de Barón Biza (Ferrer, 2007; Valobra, 2010). 
Pero la primera narrativa argentina que se consagra a una relación lesbiana es Monte de Venus (1976) de Reina Roffé9. La aparición de este libro significó también una contundente censura por parte de la dictadura militar que iniciaba ese año su cruento ciclo. La autora sitúa la trama en el contexto de las urgencias radicalizadas del periodo y en el ambiente de una institución secundaria femenina vespertina -en la época la enseñanza media estaba dividida en instituciones para varones y para mujeres- en donde la protagonista, Julia, puede mostrar sus inclinaciones lesbianas. La voz narrativa, en primera persona, permite acceder al mundo irreverente, controvertido y a menudo cínico de una muchacha que no tiene tapujos en exhibir sus amores con otras mujeres, circunstancia poco común en la Argentina del siglo pasado. Como señala Arnés "en Monte de Venus la lesbiana no sólo no muere sino que tiene voz y produce escritura. El pequeño instrumento de captura que es, primero el grabador, después la pluma, la habilita a la producción expresiva" (Arnés, 2011, 50), lo que resulta un acontecimiento.

Fue difícil admitir en público la condición de lesbiana, tal vez porque se sobreponía el sentimiento de que sonaba a "fraude", dada la mayor confianza que la sociedad concedía a los vínculos estrechos entre mujeres. Había lesbianas célebres en los años 1970 -momento de aparición del libro de Roffé-, y para citar solo algunos casos basta recordar el vínculo de María Elena Walsh - una escritora destacada y también autora de piezas musicales dedicadas a la niñez- con Elena Valladares - una consagrada música especializada en folclore-, y más tarde con Sara Facio, eximia fotógrafa. En 1972, Alejandra Pizarnik -poeta de gran enjundia- se quitó la vida después de un largo proceso depresivo, y era un secreto a voces su orientación lésbica, aunque este ángulo solo fuera reconocido bastante después por la abundante crítica que se le destinó (Piña, 1990, 1999; Bordelois, 1998).

Las denominaciones corrientes para aludir a las mujeres homosexuales fueron "tortas", "tortilleras", "bomberos" y no pocas veces "fiesteras" (Fuscova, Schmid, Merek, 1994, 107). El estereotipo de las "masculinizadas" se tornó bastante más corriente para atribuir también una sexualidad propia de los varones, pero no puede dejar de señalarse que algunas lesbianas contribuían a las convenciones discriminantes. No pocas narraron los reparos, la mojigatería y sobre todo la censura que se ejercía sobre las compañeras de intercambios sexuales, la persistencia de los preconceptos en el seno mismo de las pequeñas comunidades lésbicas. Solía denostarse a las "bomberos" que exhibían sin ambages las señales de sus orientaciones, y fue bastante corriente la exigencia de ocultamiento de los vínculos amatorios. Salirse de la raya podía significar una severa admonición (Sardá y Hernando, 2002, 45).

De la misma manera que Ernesto Meccia (2006 y 2011) ha puesto en evidencia trazos de homofobia entre los varones homosexuales dispuestos

$9 \quad$ Agradezco especialmente la referencia brindada por Laura Arnés. 
a reprimir excesos del comportamiento de la pareja "marica" -sobre todo la exteriorización gay de la vestimenta y del modo de hablar-, tampoco eran raras esas actitudes discriminatorias entre las lesbianas que deseaban disimular su condición (Meccia 2006, 146-154; Meccia, 2011). No faltaron incluso señalamientos distintivos entre "rosas" y "celestes", las primeras eran consideradas "pasivas", y las segundas "activas" aludiendo a ciertas técnicas de consumación de la sexualidad (Sardá y Herrnando, 2001, 44), lo que en términos actuales podría asimilarse a lesbianas fem y buch. Pero lo que parece haberse consagrado, desde fines de la década 1970, fue la autodesignación de "tortas", un giro que en algún modo repugnaba el despreciable "tortilleras", pero que retenía de modo celebratorio parte de su semántica.

La militancia lesbiana surgió al inicio de la recuperación democrática argentina. En 1986 había en Buenos Aires algunos grupos de activistas, tal como el Grupo Autogestivo de Lesbianas (GAL), y circulaba una publicación del núcleo "Codo con codo". Se ha sostenido que en 1988 un grupo de manifestantes que concurrió a la Plaza del Congreso se identificó con su identidad. A inicios de la década 1990 se reunían, en núcleos, en Buenos Aires organizaciones como "Fresas", luego denominada "Frente Sáfico", y "Las Unas y las Otras" (Mogrovejo, 2000, 290-291).

No puede dejar de evocarse la actitud iconoclasta, la autonomía que mostró Ilse Fuscova, quien merece algunos párrafos aparte. Tal como ha confesado en diversas oportunidades, Ilse estuvo casada por 30 años y tuvo tres hijos. Véase en uno de sus testimonios, el despertar de su orientación a raíz del Encuentro Feminista llevado a cabo en Bertioga, Brasil, a poco de reinstalarse el Estado de derecho en la Argentina:

En el '85, en Brasil, me enamoré de una militante española. Fue fuertísimo [...] Yo tenía 56. Jamás me volví a enamorar de un varón. Durante aquel maravilloso encuentro de mujeres en Bertioga, no sólo yo sino muchas mujeres argentinas se descubrieron lesbianas o bisexuales. Éramos dichosas en ese clima exuberante (Fuscova, 2008, citada en Jiménez, 2008).

Ilse visitó Alemania y los Estados Unidos en donde entró en contacto con diversos grupos de militantes, y fue cimentando el íntimo convencimiento de que era necesario posicionarse, hablar en público y especialmente forjar una agencia por los derechos como estaba ocurriendo en aquellos países. En 1987, Ilse y Adriana Carrasco iniciaron una publicación destinada a socavar la moral heterosexista acogiendo textos -a veces se trató de testimonios-, de mujeres que deseaban poner en evidencia su orientación, quebrar el canon de las convenciones y crear las condiciones del reconocimiento. Se trató de los Cuadernos de Existencia Lesbiana, que comenzaron a publicarse en ese mismo año marcando un jalón relevante. Pero no todas se animaban a identificarse, a veces usaban nombres ficticios o firmaban con iniciales; todavía era temeraria la salida del clóset. 
En el año 1991, Mirtha Legrand -una conocida actriz de larga trayectoria-, que conducía un controvertido programa en la televisión, en el que sobresalían las posturas reaccionarias, la invitó a sus "Almuerzos", tal era el formato del programa. Fue allí que llse manifestó sin tapujos su lesbianismo y contó su historia de heterosexual que había descubierto en la madurez el verdadero deseo, lo que tuvo enorme repercusión. Recuerda así la circunstancia:

Ni siquiera consulté a mis hijos si ir o no ir a la tele. Eso estaba más allá. Yo lo sentí como una apertura de conciencia social y no podía no hacerlo. Cuando fui al programa de Mirtha Legrand en el '91, mis propias compañeras feministas me decían: no vayas, te van a querer humillar. No las escuché, asistí a pesar de todo, y fue buenísimo. Terminó el almuerzo con 36 puntos de rating. ¡Con qué seguridad hablé! De alguna manera, yo desarmaba los argumentos de Mirtha. Agradezco haber podido hacer ese camino (Fuscova, 2008, citada en Jiménez, 2008).

De esa intervención pública surgió el vínculo amoroso con Claudina Marek, que también se tornó una militante. Había contrastes sociales entre llse y Claudina, aunque las dos reconocían antecedentes de familias procedentes del este europeo. Ilse era periodista, conocía varios idiomas y había participado de ambientes culturales más diversificados. Claudina era catequista, maestra y vivía en la provincia de Entre Ríos. El amor las reunió y Claudina pudo quebrar el silencio en que mantenía su sexualidad desde niña. Se debe a esta pareja emblemática una parte importante de las luchas por derechos que se inflamaron en la década 1990. Sin embargo, la brecha abierta todavía no significaba que las lesbianas hubieran franqueado el camino de su visibilidad, pues resultaba indudable que les costaba más que a los integrantes de la comunidad gay masculina. Ilse reflexiona en la misma entrevista, convencida de las dificultades: "Creo que no es fácil decirlo todavía. Se podrá decir casi con seguridad a nivel académico, o en espacios privilegiados" (Fuscova, 2008, citada en Jiménez, 2008).

Pero en estos últimos años, se ha registrado un cambio significativo en los comportamientos. No tengo dudas de que esto ha sido posible gracias a la mayor apertura general de la sociedad argentina, a los avances de la legislación igualitaria, pero sobre todo a la determinación de los segmentos de mujeres más jóvenes. Han proliferado las organizaciones en todo el país, tanto como los manifiestos y los encuentros. Se puede conjeturar que una porción de las nuevas incorporaciones a los feminismos remite a muchachas que desean identificarse de acuerdo con su subjetividad, sentimientos y pulsiones sexuales homoeróticas. Es mucho más fácil encontrar hoy a militantes lesbianas en muchos frentes de mujeres, y han aparecido numerosas iniciativas culturales integradas por lesbianas. En suma, en esta primera década del siglo XXI han aumentado los grupos, las organizaciones y las siglas que tienen como referencia el amor entre mujeres, tales los casos de las que integran la Federación Argentina de Lesbianas, Gays, Bisexuales y Trans (FLGBT) una de las más importantes agencias de disidentes de la sexualidad en la Argentina. 


\section{Surgimiento y evolución de la agencia travesti, transexual, transgénero e intersexual}

Con mayores dificultades aún las personas trans trajinaron la búsqueda colectiva de reconocimiento. Se trata de un conjunto heterogéneo por lo que resulta gnoseológica y políticamente incorrecto conferirles "identidad" con fuerza categorial; su urdimbre está compuesta de muy diversas manifestaciones, de alteridades de innegable disparidad. Una economía del lenguaje ha reducido la compleja metamorfosis de las sensaciones, las sensibilidades, las apariencias y la conducta sexual a determinadas categorías, a saber: travestis (que renuncian al estereotipo varón/mujer que marcaría la "naturaleza", pero no cambian genitales), transexuales (que renuncian al estereotipo y también a las marcas anatómicas solicitando intervenciones quirúrgicas adaptativas), transgéneros (que no desean adoptar el género sociocultural, lo que puede no significar una orientación sexual determinada), intersexuales (que debido a la ambigüedad "biológica" suscitan intervenciones quirúrgicas para adoptar uno $u$ otro sexo). Pero tales repertorios no fraguan identidades y menos aún mismidad; debemos estar prevenidos frente al encasillamiento y el destino de repetición de quienes discurren en modo contrario a la heterosexualidad normativa y a los pactos de género (Maffía, 2003; Berkins y Fernández, 2005). El derecho se ha arrogado el control de la sexualidad haciendo tajante la de tipo consentido en contraposición con la que asume el carácter sostenido, en todo caso materia indudablemente adversativa si se piensa en que es imposible ordenar políticamente el erotismo (Borrillo, 2009).

La acción colectiva de las personas trans, en especial de las travestis, comenzó probablemente a inicios de la década de 1990 -se trata del más reciente de los movimientos relacionados con los derechos personalísimos-, y se tornó más visible e intensa en Buenos Aires, ciudad que atraía a quienes se les hacía insoportable la discriminación y las humillaciones en sus respectivas comunidades interioranas. No puede sorprender que un enorme número de travestis encuestadas, en un importante estudio, procediera de las provincias andinas del norte, áreas muy conservadoras, con particular predominio de la Iglesia católica (Berkins y Fernández, 2005).

Resulta necesario situar el contexto político la década de 1990, cuando en medio de políticas neoliberales a ultranza llevadas a cabo por el gobierno de Carlos Menen -que originaron grados inéditos de pobreza y exclusión- se planteó la necesidad de la reforma de la Constitución para posibilitar su reelección. La nueva Constitución (1994) estableció la autonomía de la Ciudad de Buenos Aires ${ }^{10}$, que pasó a tener la condición institucional de un estado provincial y por lo tanto debía establecer su propio estatuto constitucional. La Constituyente

10 La Ciudad de Buenos Aires, capital de la Argentina, no gozaba de autonomía política, de modo que los Intendentes eran escogidos por el Poder Ejecutivo Nacional hasta 1997. 
deliberó en 1996 y produjo una de las cartas fundamentales más progresistas de América Latina hasta entonces, gracias a una buena cantidad de representantes de ideas progresistas y de un cierto número de feministas ${ }^{11}$. Se garantizaba la igualdad de género y de todos los sujetos afectados en derechos por causa de su orientación sexual. El nuevo estatuto de la ciudad requería el fin de los Edictos Policiales en concordancia con las nuevas garantías.

Durante los debates de la Constituyente se movilizaron diversos grupos estigmatizados por su condición sexual, entre los que se contaban agrupaciones de prostitutas y colectivos de travestis, muchas de sus integrantes forzadas a ejercer la prostitución. Sus manifestaciones fueron de gran significado no solo porque pusieron en evidencia la discriminación, el hostigamiento, la exclusión de las prerrogativas de la ciudadanía, e hicieron posible su visibilidad, sino porque ayudaron a extender la necesidad de sostener colectivos. Sus demandas para extinguir la persecución policial -se constataban toda suerte de abusos y no solamente a quienes ejercían la prostitución- fueron clave para comprender el plexo de derechos que debían plasmarse. La primera Legislatura de la Ciudad de Buenos Aires derogó los Edictos y sancionó de inicio un Código de Convivencia que eliminaba cualquier criminalización de quienes ejercían la prostitución ${ }^{12}$.

No escapa que se trataba de una medida garantista que amparaba no solo a las personas en condición de prostitución, en el marco de relaciones heterosexuales, sino a las travestis que se veían forzadas a la venta de sexo en condiciones aún más vulnerables. Fue por esos años también que se abrieron paso los estudios queer en la Argentina. A inicios de la década de 1990, el grupo Eros tuvo como cometido el análisis de la diversidad sexual y hacia 1994 se originaron encuentros académicos no solo en el ámbito de la Universidad de Buenos Aires (UBA), sino en instituciones académicas del interior del país. En 1997, Flavio Rapisardi -un reconocido ensayista y militante gay-, organizó el Área de Estudios Queer y Multiculturalismo en el Centro Cultural Ricardo Rojas - dependiente de la UBA- con la Secretaría de Extensión de la Facultad de Filosofía y Letras (Delfino, 2012) ${ }^{13}$.

Entre los avances más singulares de la acción colectiva de las personas travestis se cuenta el activismo precursor de la Asociación de Lucha por la Identidad Travesti (ALIT), una de cuyas forjadoras, Lohana Berkins, constituye una

11 Dominaban las representaciones del frente de centro-izquierda FREPASO, entre quienes estaban Raúl Zaffaroni -un conocido jurista de posiciones garantistas-, Eduardo Jozami -destacado intelectual- y feministas como María Elena Barbagelata, Liliana Chiernajowsky y María José Lubertino.

12 Deben lamentarse los cambios habidos en el original Código de Convivencia de la Ciudad de Buenos Aires, que sancionó la Legislatura en 1997, y terminó poniendo la oferta y demanda de sexo en la vía pública (1998) con ulteriores transformaciones aún más agravantes, hasta convertirlo en Código de Contravenciones en 2004 (Barrancos, 2005).

13 Silvia Delfino (2012). Inicios de los estudios queer en la Argentina. Testimonio enviado a la autora vía correo electrónico el 8 de julio del 2012. 
de las figuras más relevantes en la Argentina desde una posición identificatoria original. Berkins, que ha forjado un pensamiento de singular lucidez, sostiene:

En una sociedad que te obliga a definirte como hombre o como mujer, es más divertido decir: soy travesti. Lo ideal sería que cada uno pudiera hacer, ser y tener la imagen que quiera. La pregunta que yo me hago es si en esta sociedad tan alineada, tan educada, tan etiquetada, todavía se puede hablar de instintos primarios y deseo puro. ¿Hasta dónde estructuramos el deseo? La opresión, desde el punto de vista de las travestis, tiene que ver con que sólo se puede ser hombre o mujer en el esquema sexo-género (que implica que a una condición biológica le corresponde un determinado rol social y un deseo; mujer=madre=ama de casa). Esta sociedad se pone un poquito permisiva -un poquito-, y dice: pueden ser gays o lesbianas. Y justamente el travestismo viene a producir un quiebre. ¿Por qué tengo que elegir entre los dos géneros, como si estos géneros fueran la panacea del mundo, uno por opresor y la otra por oprimida? (Berkins, citada en Palapot, s.f.).

Se encuentran iniciativas trascendentes llevadas a cabo por la Asociación, entre las cuales la Cooperativa Nadia Echazú -en homenaje a una militante que murió de SIDA-, emprendimiento dedicado a la confección de ropa y que solo emplea a personas trans, y el Bachillerato Popular Trans "Mocha Celis"14, una escuela media que funciona en el barrio capitalino de Chacarita desde el 2012. Estas intervenciones están destinadas a promover a los individuos trans, a permitirles vivir dignamente su experiencia de transformación sexual o de género. Otro emprendimiento del movimiento es la revista El teje, originada en el 2007 en el ya citado Centro Cultural Ricardo Roja a raíz de un taller periodístico conducido por María Moreno -una destacada escritora-, y con base en ideas aportadas por Paula Viturro -conocida especialista en estudios queer. La dirección de la revista está a cargo de Marlene Wayar, militante por los derechos de la diversidad sexual y coordinadora de la Red de Travestis y Transgéneros de América Latina y el Caribe.

En el 2006 surgió la Federación Argentina LGTB -lesbianas, gays, bisexuales y transexuales- que pudo reunir a numerosos núcleos en todo el país, pero antes, hacia el 2001 -aunque hubo pasos precursores en 1993- se había creado la Asociación de Travestis, Transexuales y Transgéneros de Argentina (ATTTA) y organizaciones de activistas del país (Berkins y Fernández, 2005; Figari, 2012). La incorporación de un mayor número de colectivos permite una actuación concatenada y más eficiente, como se ha visto en relación con la Ley de Educación Sexual (Programa Nacional de Educación Sexual Integral, Ley 26.150/2011) para cuya aplicación ha venido sosteniendo diversas actividades formativas en medios educativos. Pero tal vez lo más destacado de la FLGTB ha sido su empeño decisivo para la obtención de dos leyes civiles de gran significado, el matrimonio igualitario y la Ley de Identidad de Género (Figari, 2011, 2012).

14 Homenaje a Mocha Celis, travesti oriunda de la provincia de Tucumán, analfabeta, forzada a ejercer la prostitución y muerta por la policía (Berkins, 2011). 
Unas reflexiones aparte merecen el grupo de las personas intersexuales, sobre quienes han pesado especialmente los repertorios de "normalidad biológica" y la procura de rectificación anatómica. Durante la mayor parte del siglo pasado, la medicina convenció a padres y madres a realizar precoces intervenciones quirúrgicas en niñas y niños con el objeto de obtener adaptaciones según forzosas demandas fisiológicas. Las manifestaciones anatómicas hermafroditas debían tener una rápida corrección según la opinión normalizadora de los facultativos, y las cirugías -a menudo reiteradas sobre cuerpos de criaturas de muy pocos años- probablemente resultaron catastróficas para la integridad psíquica de la mayoría de los pacientes (Cabral, 2004).

Solo en época reciente pudo admitirse -tal como describieron, entre otros, los análisis de Fausto-Starling- que la profusión de sexos en un individuo son por lo menos cinco, a saber: el sexo cromosómico, el gonodal, el morfológico, el hormonal, y el asignado socialmente (Fausto-Starling, 2000, 18-23). Las intervenciones quirúrgicas, sin que medie la voluntad de la/del afectado, han menguado a medida que se han incrementado las demandas, por lo que la propia ciencia médica ha tenido que admitir la arbitrariedad de su cometido. En todo caso, se ha interpuesto el paradigma de los derechos humanos, la extensión universal de las prerrogativas de la diversidad de acuerdo a los sucesivos desdoblamientos emanados de la Declaración Universal de los Derechos Humanos (1948) con mayor número de Convenciones y de Pactos.

En 2006, un grupo de reconocidos expertos y activistas -a instancias de la ONU-produjo el documento Principios de Yogyakarta sobre la aplicación del Derecho Internacional de Derechos Humanos a las cuestiones de Orientación Sexual e Identidad de Género (2006). Por América Latina participaron Sonia Onufer Corrêa, de Brasil, y Mauro Cabral, de Argentina, quienes estuvieron entre los redactores de los veintinueve derechos presentados en el documento, uno de los cuales -el número 18-, expresa:

Ninguna persona será obligada a someterse a ninguna forma de tratamiento, procedimiento o exámenes médicos o psicológicos, ni a permanecer confinada en un centro médico, con motivo de su orientación sexual o identidad de género. Con independencia de cualquier clasificación que afirme lo contrario, la orientación sexual y la identidad de género de una persona no son, en sí mismas, condiciones médicas y no deberán ser tratadas, curadas o suprimidas (Principios de Yogyakarta) ${ }^{15}$.

Cabral, que ha vivido una experiencia traumática a raíz de las cirugías forzadas de rectificación, es uno de los más destacados activistas latinoamericanos y también un analizador profundo de las construcciones de género a propósito de las rectificaciones que padecen las personas intersex. Véanse algunas de sus ideas:

15 Recuperado de: http://www.oas.org/dil/esp/orientacion_sexual_Principios_de_Yogyakarta_2006.pdf 
Para socializar a alguien como una niña, para que su identidad femenina resultara "exitosa" y sin fisuras, era imprescindible que su cuerpo fuera, en su apariencia exterior, el de una niña standard, capaz de sostener la mirada y la palabra, constitutivas, de su madre y su padre, su propia percepción de sí como ser sexuado. El cuerpo regresaba, por lo tanto -no bajo la forma de una determinación a priori, biológica-, sino como el sostén material, imprescindible, de la asignación de género y del éxito de esa asignación a lo largo de la vida. Este regreso del cuerpo sexuado como determinante-esta vez no de la identidad sexual "verdadera", sino de la posibilidad misma de una identidad sexual-, precisaba no solamente de asegurar la apariencia exterior de los genitales sino también ciertas funciones estimadas fundamentales (Cabral y Benzur, 2005, 288).

En el clima de ascenso de los combates que reclamaban reconocimiento, dignidad e igualdad de derechos, surgieron las notables reformas civiles de los últimos años.

\section{Las leyes de Matrimonio Igualitario y de Identidad de Género}

Hasta hace una década parecía poco probable que la Argentina recorriera el camino de la legislación renovadora en materia de derechos personalísimos, aunque hubiera algunas tentativas parlamentarias. En 1998, a instancias de la diputada Laura Musa, se presentó en el Congreso el primer proyecto de "parteneriato para parejas del mismo sexo", inspirada en buena medida en la legislación francesa. El proyecto fue retomado en el 2000 por la diputada Margarita Stolbizer y la misma diputada Musa insistió, en el 2002 y en el 2004, sin que hubiera tratamiento para tales iniciativas (Carrasco, 2011, 163-164). El antecedente más próximo en materia de "uniones" de personas del mismo sexo fue la ley originada en la Legislatura de la Ciudad de Buenos Aires, en el 2002, que consagraba algunas prerrogativas para quienes se registraban como sujetos de la "unión civil", desde luego de modo exclusivo para este distrito y sin los derechos conferidos al matrimonio.

En el 2005, el diputado Eduardo Di Pollina intentó, sin suerte, por primera vez la modificación del Código Civil en el sentido de admitir contrayentes del mismo sexo. Durante esos años, el activismo de organizaciones tales como la CHA, ALIT, y especialmente a partir del 2006, la FLGTB, gravitó en la decisión de las y los congresistas. En el 2007, se registraron más presentaciones de proyectos y también una iniciativa en el Senado de la Nación efectuada por la senadora Vilma Ibarra.

No pueden dejar de evocarse las tentativas efectuadas por algunas parejas para matrimoniarse legalmente. Son bien conocidos los casos de María Rachid -quien ejercía la Presidencia de la FLGTB- y su compañera Claudia Castro, en febrero de 2008, cuando se presentaron al Registro Civil de la Ciudad de Buenos Aires solicitando que se admitiera su inscripción con resultado 
infructuoso. Pero la situación más resonante fue la vivida por Alejandro Freyre y José María Di Bello quienes obtuvieron, en noviembre del 2009, autorización para contraer matrimonio civil por parte de la jueza Gabriela Seijas que en un fallo memorable, declaró inconstitucional los artículos del Código Civil referidos al matrimonio, pero fueron impedidos de formalizar el registro por una medida cautelar. Freyre y Di Bello finalmente pudieron casarse en la gobernación austral de Tierra del Fuego a cuyo frente se desempeñaba la socialista Fabiana Ríos, aunque ese matrimonio fue luego declarado ilegal (Von Opiela, 2011).

Hubo que esperar al 2009 para que a instancias de la diputada Silvia Augsburger, con la firma de diputados de diversas fuerzas políticas, se tratara en el Congreso el proyecto de matrimonio igualitario, al que se unió la propuesta de la diputada Vilma Ibarra acompañada con otras firmas de representantes. Se realizaron entonces una serie de audiencias públicas, resultando especialmente destacados algunos actores, como María Rachid que habló en nombre de la FLGTB y la titular del Instituto Nacional contra la Discriminación, la Xenofobia y el Racismo, María José Lubertino, que había desarrollado una campaña contra la discriminación y que en nombre del propio Poder Ejecutivo solicitaba el cambio del Código Civil (Carrasco, 2011; Figari, 2011).

También participaron de las audiencias reconocidos constitucionalistas y representantes de la cultura y la ciencia. Tuvo efecto significativo el documento presentado por la comunidad científica Per scientiam ad justitiam! suscrito por más de 600 investigadoras e investigadores del Consejo Nacional de Investigaciones Científicas y Técnicas (CONICET) y docentes de diversas universidades argentinas, que hizo suyo la FLGTB (Figari, 2011, 107-109). Sus argumentos fueron empleados de manera fructífera durante los largos debates del tratamiento de la ley en los respectivos plenarios de ambas Cámaras. Y aunque se robustecían las posiciones que acompañaban la reforma civil, menudeaban las expresiones muy conservadoras -algunas de enjundia patética-. Estas últimas fueron acompañadas por las manifestaciones públicas, en primer lugar de las iglesias cristianas evangélicas de nuevo cúneo, en particular de los grupos pentecostales, seguidos por una estridente movilización de organizaciones católicas.

Algunas diputadas y diputados solicitaron que debía sancionarse la alternativa de la "unión civil" para no afectar el significado angular del concepto "matrimonio", amparándose en la tradición sacramental del vínculo. Durante el 4 de mayo de 2010, y las primeras horas del 5 de mayo, diversos grupos de disidentes sexuales y también una expresiva cantidad de manifestantes heterosexuales, acompañaron los argumentos finales vertidos en la Cámara de Diputados. Aunque muy reñida, la votación fue exitosa: 126 votos a favor, contra 110 en contra, y 4 abstenciones (Carrasco, 2011, 171). A los pocos días, el proyecto llegó al Senado que también evidenciaba posiciones muy antagónicas. El tratamiento en el recinto se inició el 14 de julio y llegó también a la madrugada del 15. Finalmente, la sanción de la ley que igualaba la conyugalidad se consagró con 33 votos afirmativos, contra 27 negativos y 3 
abstenciones (Carrasco, 2011, 174). No deja de ser remarcable que, a pesar de que las fuerzas políticas no obtuvieron unanimidad -con excepción de los representantes socialistas-, la mayoría de las mujeres de ambas Cámaras -cerca del 60\% - fueron favorables a la medida.

En relación con la Ley de Identidad de Género, los antecedentes internacionales que más impactaron en la legislación argentina fueron las modificaciones ocurridas en España (2007) y en Uruguay (2008). Muy disímiles frentes de activistas, como las organizaciones ya citadas, peticionaron el fin a la violencia que implicaba la falta de reconocimiento de las identidades que constituían lo que denominé la "diáspora" de la sexualidad (Barrancos, 2009, 2-4). En todos los casos se afirmaba la necesidad de ampliar la ciudadanía y de incluir a las personas trans en el cauce de los derechos humanos, una deuda de la democracia. Aunque era una tarea difícil obtener una norma que hiciera justicia y no encasillara a las personas de modo categorial, que evitara en cualquier caso nuevas humillaciones en el proceso del registro de nombres y asignaciones de sexo, y la judicialización de los procesos inherentes a los cambios quirúrgicos voluntarios, la Argentina conquistó finalmente la más progresista de las leyes en la materia.

En el 2007, la diputada Silvia Augsburger -a quien ya se ha visto realizar acciones a favor del proyecto de matrimonio igualitario- elaboró el primer proyecto de ley en el Congreso, y ha reconocido entre otras fuentes inspiradoras la asesoría brindada por el activista español Pedro Zerolo, que visitó nuestro país animando a la obtención de la norma legal (Von Opiela, 2012, 420). Pero la iniciativa no pudo ser tratada. Un avance fue la Ley 3062/2009 de la Ciudad de Buenos Aires que establecía la obligación, en todo el ámbito administrativo, de respetar la identidad de género de travestis y transexuales que utilizaban un nombre distinto al consignado en su documento de identidad. Desde luego, la ley se restringía al ámbito porteño y a su sector administrativo. Otro paso singular fue el de la Universidad Nacional de Córdoba que, en 2011, resolvió que debía acatarse la identidad de género manifestada por los sujetos pertenecientes a su ámbito (alumnado, profesorado y personal administrativo) y aceptar el nombre adoptado.

Al proyecto original de Augsburger se habían sumado, en el 2010, los de las diputadas Silvana Giudice, Vilma Ibarra, Juliana Di Tulio, Diana Conti, acompañadas por un importante número de representantes de diversos partidos políticos. Los debates, en ambas Cámaras, recogieron el imperativo de las convenciones, los pactos, los Principios de Yogiakarta, la necesidad de incluir y el cumplimiento de los derechos humanos fundamentales. El amparo de las garantías constitucionales en materia de derechos personalísimos animó inclusive a los espíritus conservadores -y no pocos parlamentarios cambiaron de opinión-, frente a la contundencia de los argumentos vertidos por quienes deseaban la igualdad civil. Las oposiciones a la iniciativa fueron menores que en 
el caso del matrimonio facultado a las personas del mismo sexo. En mayo de 2012 se sancionó la Ley 26.743 de Igualdad de Género, y el artículo 2 dice:

Se entiende por identidad de género a la vivencia interna e individual del género tal como cada persona la siente, la cual puede corresponder o no al sexo asignado al momento del nacimiento. Incluyendo la vivencia personal del cuerpo. Esto puede involucrar la modificación de la apariencia o la función corporal a través de medios farmacológicos, quirúrgicos o de otra índole, siempre que ello sea libremente escogido. También incluye otras expresiones de género, como la vestimenta, el modo de hablar y los modales (Ley 26.743, Art. 2, 2012).

Desde que se tenga 18 años de edad como mínimo, cualquier persona puede solicitar la rectificación registral de su sexo y basta para esto presentarse ante el Registro Nacional de las Personas y hacer la solicitud expresando el nuevo nombre de pila elegido. Para los menores de edad, son los representantes legales quienes realizan el trámite con expresa conformidad de las/los solicitantes. En ningún caso - dice la ley en su artículo $4^{\circ}$ - será requisito la intervención quirúrgica modificatoria del sexo genital, ni ninguna otra transformación del cuerpo. El artículo 11 dispone que para las personas mayores de 18 años, las adecuaciones por medio de cirugías o los tratamientos hormonales, son de acceso directo sin mediación judicial o de otra naturaleza. Aspectos fundamentales derivados de las nuevas leyes tienen que ver con la corrosión definitiva de la maternidad y la paternidad exclusivamente heterosexuales. Las parejas homosexuales han adquirido de pleno derecho de inscribir sus descendientes en el marco legal, de modo que, como nunca, se ha extendido la concepción plural de las familias. La co-maternidad y la co-parentalidad constituyen experiencias que se han beneficiado singularmente con las leyes de matrimonio igualitario y de identidad de género ${ }^{16}$.

\section{Conclusiones}

Durante el siglo XX la Argentina transitó un camino que no hacía prever las grandes transformaciones legales de los últimos años en materia de género, orientación sexual y sexualidades. Por un lado, las normas morales se mantuvieron dentro del canon prescriptivo patriarcal, sujetando por una parte la moral femenina, ordenando la estricta contención sexual y el exclusivo conocimiento carnal marital con el objetivo primordial de la reproducción. Por el otro, la prescripción médica y la disquisición psiquiátrica concordaron, junto con las normas jurídicas, en la condena de las anormalidades de la sexualidad. Aunque no se registraron atmósferas sostenidas de "pánico sexual", ni dominaron las obsesiones públicas contra los homosexuales, no hay dudas de que la larga ausencia

16 La propia Presidenta de la Nación, Dra. Cristina Fernández de Kirchner, el 2 de julio de 2012, entregó en un singular acto público los primeros documentos de identidad ya modificados a personas travestis y a niñas y niños nacidos en hogares homoparentales. 
de Estado de derecho y los continuos periodos dictatoriales, contribuyeron al surgimiento de normas inconstitucionales como los Edictos Policiales.

Durante el peronismo ocurrieron acontecimientos paradójicos, si por un lado ganó cierta estatura el estatuto de la homosexualidad -resultaba imposible no advertir la existencia de individuos, sobre todo varones, que amaban y mantenían sexo con personas del mismo sexo-, y hasta hubo acontecimientos que parecían disminuir la homofobia, por otro, hubo signos de intolerancia y censura. Como parte del clima de radicalidad política que se vivió en las décadas de 1960 y 1970 surgieron las primeras manifestaciones a favor de los derechos de los homosexuales, y también la oportunidad de una tímida identificación de las mujeres lesbianas, muchas de las cuales pertenecían a agrupaciones feministas. Pero esos fenómenos fueron reprimidos por la última feroz dictadura militar que persiguió a militantes y obligó al exilio externo e interno de activistas.

Con la recuperación democrática no solo se abrió paso un renovado movimiento feminista, sino que las sexualidades divergentes fueron ocupando la escena pública. A mediados de la década 1980 surgió una notable organización gay, pero los esfuerzos se dirigieron fuertemente a la lucha contra el SIDA, epidemia que como es bien sabido asolaba al mundo. Resulta incontestable que el temor al flagelo posibilitó la visibilización de la comunidad homosexual en el país, pero también fue responsable por ciertos cismas pues para una parte de la militancia se imponía, además del combate de la enfermedad, la búsqueda primordial de la igualación, la lucha por la inclusión y el estado de ciudadanía. El número de organizaciones de lesbianas y de activistas se incrementaron durante estas décadas, pero se constata la mayor dificultad que han tenido muchas mujeres para enunciar públicamente sus orientaciones. El último grupo en aparecer en la escena pública ha sido el de las personas trans -una abigarrada comunidad de identificaciones que irrumpió con singular fuerza a mediados de la década 1990-, enfrentando la exclusión, la falta de reconocimiento y la represión policial. Desde entonces han aparecido militantes de gran lucidez que han reivindicado la eliminación de los presupuestos inamovibles de sus identificaciones sexuales y de género, sosteniendo agrupaciones que han contribuido a transformar la subjetividad y los contextos existenciales.

Como consecuencia de los cambios sociales y culturales de la última década, la Argentina avanzó en materia legislativa en el ámbito latinoamericano con la sanción de dos leyes que han redistribuido también los derechos civiles, la que se refiere al matrimonio entre personas del mismo sexo y la de identidad de género. Esta última se ha apartado de cualquier fijación sexual esencial y confiere a todas las individualidades desmarcadas de las formas polares de géneros, iguales derechos de ciudadanía, la prerrogativa de exhibir -sin ambages- un cuerpo y un nombre propios. 


\section{Bibliografía}

Arnés, Laura A. (2011). La lesbiana y la tradición literaria argentina: Monte de Venus como texto inaugural. Lectora, (17), 41-52. Recuperado de http:// revistes.ub.edu/index.php/lectora/article/view/7204

Barón Biza, Raúl. (1933). El derecho de matar. Recuperado de http://es.scribd. com/doc/182240513/Baron-Biza-Raul-El-Derecho-De-Matar

Barrancos, Dora. (2011). El erotismo, una conquista femenina muy reciente. Entremujeres, Clarín. Recuperado de http://entremujeres.clarin.com/genero/ erotismo-conquista-feminista-reciente_0_494950559.html

Barrancos, Dora. (2009). Políticas de reconocimiento: entre las líneas teóricas y las pragmáticas (Tomo II). Buenos Aires: Ají de Pollo.

Barrancos, Dora. (2005). La diferencia sexual y el Código de Convivencia en la Ciudad Autónoma de Buenos Aires. Notas para la historia de la regresión de derechos. Revista Mora, (11), 202-204.

Barrancos, Dora. (1999). Moral sexual, sexualidad y mujeres trabajadoras en el periodo de entreguerras. En Devoto, Fernando y Madero, Marta. (Dirs.). Historia de la vida privada en la Argentinas, Vol. 3. Buenos Aires: Taurus.

Barrancos, Dora. (1990). Anarquismo, educación y costumbres en la Argentina de principios de siglo. Buenos Aires: Contrapunto.

Bazán, Osvaldo. (2004). Historia de la homosexualidad en la Argentina. De la conquista de América al siglo XXI. Buenos Aires: Marea.

Bellucci, Mabel. (2010). Orgullo. Carlos Jáuregui una biografía política. Buenos Aires: Planeta.

Ben, Pablo y Acha, Omar. (2005). Amorales, patoteros, chongos y pitucos. La homosexualidad masculina en el primer peronismo (Buenos Aires, 19431955). Revista Trabajos y Comunicaciones, (30-31), 217-260. Recuperado de http://sedici.unlp.edu.ar/bitstream/handle/10915/11506/Documento_completo.pdf?sequence=1

Berkins, Lohana. (Comp.). (2007). Cumbia, copeteo y lágrimas. Informe nacional sobre la situación de travestis, transexuales y transgéneros. Buenos Aires: ALIT.

Berkins Lohana y Fernandez Josefina. (2005). La gesta del nombre propio. Informe sobre la situación de la comunidad travesti en la Argentina. Buenos Aires: Ediciones Madres de Plaza de Mayo.

42 Bianciotti, Héctor. (1992). Lo que la noche le cuenta al día. Madrid: Tusquets. 
Bordelois, Ivonne. (1998). Correspondencia Pizarnik. Buenos Aires: Planeta.

Borrillo, Daniel. (2009). Le droit des sexualités. Paris: PUF.

Boswell, John. (1996). Las bodas de la semejanza. Uniones de personas del mismo sexo en la Europa premoderna. Barcelona: Muchnik.

Butler, Judith. (2005). Cuerpos que importan. Buenos Aires: Paidós.

Cabral, Mauro. (2004). De monstruos conjurando: Intersexualidad y biotecnologías de la identidad. Revista Mora, (9-10), 131-140.

Cabral, Mauro y Benzur, Gabriel. (janeiro-junho, 2005). Cuando digo intersex. Un diálogo introductorio a la intersexualidad. Cadernos Pagú, (24), 283-304.

Carrasco, Maximiliano. (2011). El matrimonio igualitario en el Parlamento argentino. Antecedentes parlamentarios. Los proyectos que se convirtieron en Ley. El tratamiento en ambas Cámaras y las votaciones. En Solari, Nestor y Von Opiela, Carolina. (Dirs.). Matrimonio entre personas del mismo sexoLey 26.618-Antecedentes, Implicaciones, Efectos. Buenos Aires: La Ley.

Cleminson, Richard. (2008). Anarquismo y sexualidad. España (1900-1939). Cádiz: Universidad de Cádiz.

Cosse, Isabella. (2010). Pareja, sexualidad y familia en los años sesenta. Una revolución discreta en Buenos Aires. Buenos Aires: Siglo XXI Editores.

Fausto-Starling, Anne. (2000). The Five Sexes Revisited. Sciences, 40(4), 18-23.

Ferrer, Christian. (2007). El inmoralista. Buenos Aires: Sudamericana.

Figari, Carlos. (2011). Matrimonio igualitario: ciencia y acción política. En Solari, Nestor y Von Opiela, Carolina. (Dirs.). Matrimonio entre personas del mismo sexoLey 26.618-Antecedentes, Implicaciones, Efectos. Buenos Aires: La Ley.

Figari, Carlos. (2012). Identidad de género: entre cortes y suturas. En Von Opilea Carolina. (Coord). Derecho a la identidad de género-Ley 26.743. Buenos Aires: La Ley.

Figari, Carlos y Ponce, Elsa. (2008). Los movimientos sexo políticos en Argentina: De los fusiles a las plumas. Ponencia presentada en las Jornadas Internacionales de Problemas Latinoamericanos: "Los Movimientos sociales en Amércia Latina. Pasado, presente y perspectiva". Facultad de Humanidades, Universidad Nacional de Mar del Plata, 1-16.

Foucault. Michel. (1991). Historia de la sexualidad. I La voluntad de saber. México: Siglo XXI.

Fuscova, Ilse; Schmid, Silvia y Marek Claudina. (1994). Amor de mujeres. El lesbianismo en la Argentina, hoy. Buenos Aires: Planeta. 
Gay, Peter. (1992). La experiencia burguesa. De victoria a Freud. II Tiernas Pasiones. México: Fondo de Cultura Económica.

González, José. (s.f.). Los invertidos. Buenos Aires: Prensa Moderna.

Gordon, Mel. (2000). Voluptuous: The Erotic World of Weimar. Washington: Feral House.

Honey, John. (1992). Los nervios de la sociedad: las public schools como "sistemas". En Müller, Detlef; Ringer, Fritz y Simon, Brian. (Comps.). El desarrollo del sistema educativo moderno. Madrid: Ministerio de Trabajo y Seguridad Social.

Jiménez, Paula. (2008). Entrevista a llse Fuscova. Página12, SOY. Recuperado de http://www.pagina12.com.ar/diario/suplementos/soy/1-350-2008-10-04.html

Lewin, Miriam y Wornat, Olga. (2014). Putas y guerrilleras. Crímenes sexuales en los centros clandestinos de detención. Buenos Aires: Planeta.

Llorca Díaz, Angeles. (1996). Magnus Hirschfeld y su aportación a la ciencia sexológica. Recuperado de http://sexologiaenredessociales.files.wordpress.com/2013/08/a2-4-Ilorca.pdf

Machado Bonet, Ofelia. (1960). Un ángel de bolsillo. Buenos Aires: Losada.

Maffía, Diana. (2003). Sexualidades migrantes. Género y transgénero. Buenos Aires: Feminaria.

Meccia, Ernesto. (2011). Los últimos homosexuales. Sociología de la homosexualidad y de la gaycidad. Buenos Aires: Gran Aldea.

Meccia, Ernesto. (2006). La cuestión gay. Un enfoque sociológico. Buenos Aires: Gran Aldea.

Mogrovejo, Norma. (2000). Un amor que se atrevió a decir su nombre. La lucha de las lesbianas y su relación con los movimientos homosexual y feminista en América Latina. México: Plaza y Valdés/CDAHL.

Palapot, Clarisa. (s.f.). Travestida para transgredir (entrevista a Lohana Berkins). Recuperado de http://www.socialismo-o-barbarie.org/revista/sob3/travestida.htm

Pecheny, Mario. (2001). La epidemia de SIDA y el reconocimiento de los derechos de las minorías sexuales. Desidamos, 9(1), 1.

Perlongher, Néstor. (1987). Alambres. Buenos Aires: Último Reino.

Perlongher, Néstor. (1988). El fantasma del sida. Buenos Aires: Puntosur.

44 Perlongher, Néstor. (1989). Hule. Buenos Aires, Último Reino. 
Perlongher, Néstor. (1990). Aguas aéreas. Buenos Aires: Último Reino.

Perlongher, Néstor. (1990). Parque Lezama. Buenos Aires: Sudamericana.

Perlongher, Néstor. (1993). La prostitución masculina. Buenos Aires: La Urraca.

Perlongher, Néstor. (1997). Poemas completos. Buenos Aires: Seix Barral.

Perlongher, Néstor. (1997). Prosa plebeya. Selección de Christian Ferrer y Osvaldo Baigorria. Buenos Aires: Colihue.

Perlongher, Néstor. (1999). El negocio del deseo. Buenos Aires: Paidós.

Perlongher, Néstor. (2001). Evita vive e outras prosas. Selección de Adrián Cangi y traducción de Josely Vianna Baptista. San Pablo: lluminuras.

Piña, Cristina. (1999). Alejandra Pizarnik: una Biografía. Buenos Aires: Corregidor.

Piña, Cristina. (1990). La Palabra Obscena. Cuadernos Hispanoamericanos, (5), 17-38.

Principios de Yogyakarta sobre la aplicación del Derecho Internacional de Derechos Humanos a las cuestiones de Orientación Sexual e Identidad de Género. (2006) Recuperado de http://www.oas.org/dil/esp/orientacion_ sexual_Principios_de_Yogyakarta_2006.pdf

Roffé, Reina. (1976). Monte de Venus. Buenos Aires: Corregidor.

Ramaciotti, Karina y Valobra, Adriana. (En prensa). Peor que putas... Tríbadas, safistas y homosexuales en el discurso moral hegemónico del campo médico (1936-1954). En Barrancos, Dora, Guy, Donna y Valobra, Adriana. (Eds.). Moralidades y conductas sexuales en la Argentina (1880-2011). Buenos Aires: Biblos.

Salessi, Jorge. (1995). Médicos, maleantes y maricas. Higiene, criminología y homosexualidad en la nación Argentina (Buenos Aires 1871-1914). Rosario: Beatriz Viterbo Editora.

Sapriza, Graciela. (1999). Clivajes de la memoria. Para una biografía de Paulina Luisi. En Álvarez, L., Caetano, G. y Rilla, J. (Orgs.). Uruguayos notables-11 biografías (Volumen 1, $1^{\text {a }}$. Parte). Montevideo: Linardi y Risso, Fundación Bank Boston.

Sardá, Alejandra y Hernando, Silvana. (2001). No soy un bombero pero tampoco ando con puntillas. Lesbianas en Argentina: 1930-1976. Toronto: Editorial Bomberos y Puntillas.

Schwarzstein, Dora. (2001). Entre Franco y Perón: memoria e identidad del exilio republicano español en Argentina. Buenos Aires: Crítica. 
Simonetto, Patricio. (2014). Entre la injuria y la revolución: el Frente de Liberación Homosexual en la Argentina (1967-1976). Tesis de Licenciatura en Comunicación Social. Bernal: Universidad Nacional de Quilmes.

Szurmuk, Mónica. (1996). Ada María Elflein: Viaje al interior de las identidades. Monographic Review / Revista Monográfica, 22, 337-344.

Valobra, Adriana M. (2010). Del hogar a las urnas. Recorridos de la ciudadanía politica femenina, Agentina (1946-1955). Rosario: Prohistoria.

Von Opiela, Carolina. (Coord.). (2012). Derecho a la identidad de género-Ley 26.743. Buenos Aires: La Ley.

Von Opiela, Carolina. (2011). Los mismos derechos con los mismos nombres. Una mirada sobre el matrimonio igualitario en Argentina y en el mundo. En Solari, Nestor y Von Opiela, Carolina. (Dirs.). Matrimonio entre personas del mismo sexo-Ley 26.618- Antecedentes, Implicaciones, Efectos. Buenos Aires: La Ley. 